\title{
Inbreeding and inbreeding depression on body weight in sheep
}

\author{
E. Barczak ${ }^{1}$, A. Wolc ${ }^{1}$, J. Wójtowski ${ }^{2}$, P. Ślósarz ${ }^{2}$ \\ and T. Szwaczkowski ${ }^{1,3}$ \\ Poznan University of Life Sciences, \\ ${ }^{1}$ Department of Genetics and Animal Breeding \\ Wotyńska 33, 60-637 Poznan, Poland, \\ ${ }^{2}$ Department of Sheep, Goat and Fur Animals Breeding \\ Złotniki, Stoneczna 1, 62-002 Suchy Las, Poland
}

(Received 16 July 2008; revised version 13 November 2008; accepted 23 January 2009)

\begin{abstract}
The aims of this study were to estimate the inbreeding level and to evaluate inbreeding effects for birth $(\mathrm{BW})$ and fourth week weight $(\mathrm{FWW})$ in a multi-breed sheep population. The analyses were performed within eight lines and the total population. The data set of 36488 pedigreed individuals over twenty years was analysed. The inbreeding coefficients were derived from an additive relationship matrix. The inbreeding depression was expressed as a partial linear regression coefficient estimated via a single trait animal model including fixed effects (flock, type of birth, sex, breed, inbreeding coefficient - as linear covariable) and random effects (additive genetic and residual). The number of pedigreed individuals varied considerably over time. The study has shown that the inbreeding of this population was very low $(0.30 \%)$. However, the estimate is considerably influenced by incomplete pedigree information. Comparative analysis of inbreeding levels within lines and breeds indicated on differences between them. Both positive and negative inbreeding effects (ranged from -12.6 to $16.0 \mathrm{~g}$ for BW and from -61.9 to $18.1 \mathrm{~g} \mathrm{FWW}$ ) were found depending on line.
\end{abstract}

KEY WORDS: body weight, inbreeding rate, inbreeding depression, sheep

\section{INTRODUCTION}

Genetic improvement programs applied in livestock have been based on two main approaches: selection and crossbreeding. By contrast to crossbreeding, intensive selection within a single population reduces a genetic variability and

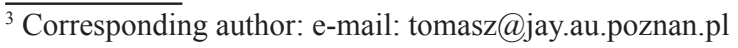


increases the inbreeding rate. The inbreeding, although once thought to be a useful tool to improve sheep populations by increasing the frequency of desired genotypes, usually leads to economic losses. The inbreeding level is considerably influenced by the ratio of males to females, reproduction ability, mating system, and population size. To determine how these affect the sheep population in Poland, firstly, a number of lines were formed. The lines were mainly derived on the basis of crossbreeding improvement programs by the use of global (e.g., Suffolk, Texel, Ile de France) and local (Wielkopolska, Polish Merino) breeds. In consequence they have different gene pools and various genetic effects can be expected. Secondly, the creation of new genetic groups was accompanied by intensive selection. Thirdly, the size of flocks has been gradually decreased.

To our knowledge, no reports, based on mixed model methodology, on inbreeding level and its effects in the Polish sheep population are available. Main traits included in the genetic improvement programs are body weight at birth and at four weeks. An inbreeding depression for lamb body weight was found by Wiener et al. (1992) and Norberg and Sorensen (2007). On the other hand, some investigations carried out on livestock populations indicated negligible positive inbreeding effects on some performance traits (Wiener et al., 1992). Positive effects seen of higher levels of inbreeding may have been due to purging of deleterious alleles in previous generations.

The objectives of this study were to estimate the inbreeding level and to evaluate the inbreeding effects on birth and fourth week body weight in lambs. It is well known that inbreeding level depends on population history. Hence, the analysis was performed both for whole population and within single lines.

\section{MATERIAL AND METHODS}

The data sets of 36488 pedigreed individuals born over twenty years were extracted from flock-books of three nucleus farms (Brody, Sielinko and Zlotniki) located in West Poland.

The sheep from the following eight lines and breeds were analysed (number of individuals):

- W11 - Wielkopolska breed - line I (7630)

- W22 - Wielkopolska breed - line II (5718)

- MER - Polish Merino Sheep (3164)

- EF - East Fresian (3891)

- WMS - White-head Mutton Sheep (6267)

- BMS - Black-head Mutton Sheep (3850)

- PM - Prolific-meat line (2420),

- DT - meat line in Dorset type (3548).

More details on the studied populations were given by Wójtowski (1999). 
The inbreeding coefficients were derived from an additive relationship matrix for the whole population and within the above mentioned genetic groups. Completeness of the pedigree information was evaluated by the method described by Cassell et al. (2003).

The inbreeding effects were evaluated for two traits: birth weight (BW) and fourth week weight (FWW). The records of 31709 and 29505 lambs were available for BW and FWW, respectively. Prior to the main study, the exploratory analysis via ANOVA using GLM procedure (SAS, 2002-2003) was performed to evaluate the significance of fixed effects. According to the analysis the following fixed effects, except the genetic groups, were included into linear model for estimation of inbreeding effects: flock, sex, type of birth (single, twins and triples), age of dam (ten levels - from one to ten years, respectively). A brief description of the data is shown in Table 1. The following single trait linear animal model was used to estimate the inbreeding effects:

$$
y_{i j k l m n}=\mu+f_{i}+s_{j}+d_{k}+g_{l}+r_{m}+b x_{i j k l m n}+a_{i j k l m n}+e_{i j k l m n}
$$

where: $y_{i j k l m n}$ - body weight of ijklmn-th lamb, $\mu$ - overall mean, $f_{i}$ - fixed effect of i-th flock, $s_{j}$ - fixed effect of j-th sex, $d_{k}$ - fixed effect of k-th type of birth, $g_{l}$ - fixed effect of dam age, $r_{m}$ - fixed effect of breed, $b$ - linear partial regression coefficient, $x_{i j k l m n}$ - inbreeding coefficient of ijklmn- th individual, $a_{i j k l m n}$-random additive genetic effect of $i j k l m n$ - th individual, $e_{i j k l m n}$ - random error connected with ijklmn-th observation.

Table 1. Description of the data set

\begin{tabular}{lccc}
\hline Trait & $\begin{array}{c}\text { Number of recorded } \\
\text { individuals }\end{array}$ & $\begin{array}{c}\text { Average } \\
\mathrm{g}\end{array}$ & $\mathrm{SD}$ \\
\hline $\mathrm{BW}^{1}$ & 31709 & 4383 & 872 \\
$\mathrm{FWW}^{2}$ & 29505 & 12331 & 2562 \\
\hline
\end{tabular}

${ }^{1} \mathrm{BW}$ - birth weight, ${ }^{2} \mathrm{FWW}$ - fourth week weight

The inbreeding depression was expressed as a partial linear regression coefficient. It is interpreted as a change of body weight influenced by one percent of inbreeding. The estimation of parameters was performed by the use of the Derivative Free Restricted Maximum Likelihood (DFREML) algorithm numerically implemented in the DFREML package program by Meyer (2000).

\section{RESULTS}

Changes of population size including inbred and non-inbred individuals are given in Figure 1. In general, the number of pedigreed in- 
dividuals varied considerably over time. It should be recalled that the data were classified according to the year of birth. Therefore, the size of the population was gradually increasing until the 12-th year (mid 80-ties). After that, the number of individuals decreased. The rapid increase of inbreeding in years 1981-1984 can be explained by the fact that in those years there was a large

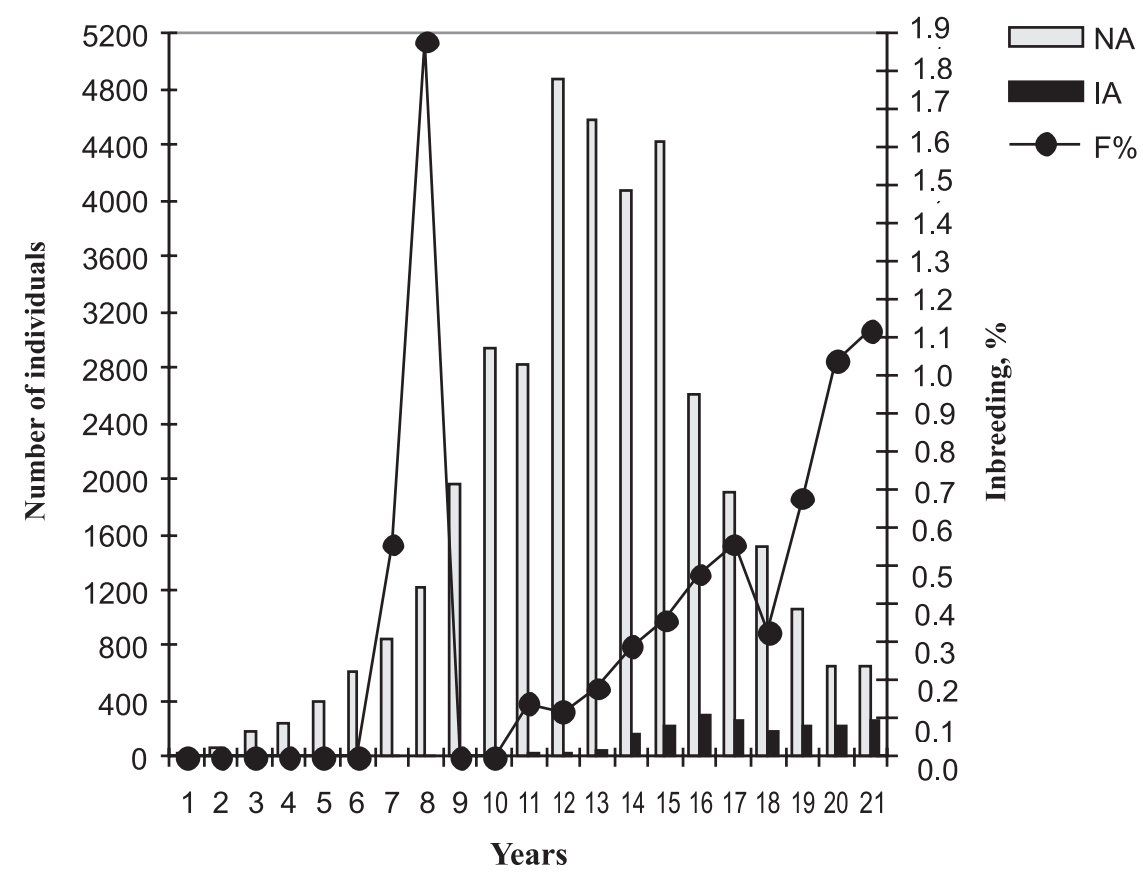

Figure 1. Changes of inbreeding level (F\%) over twenty years and number of non-inbred (NA) and inbred (IA) animals

import of individuals to the population, which were not used for reproduction. There was only a small group of individuals used for breeding, which caused the increase of inbreeding. The number of individuals was partially associated with the number of inbred animals and in consequence with the inbreeding rate. The relationships (as shown in Figure 1) seem to be more clear since the 10-th year. However, in the later years the number of non-inbred animals decreased by contrast to the number of inbred animals and the average inbreeding level. Standard deviations of the annual inbreeding coefficients varied from zero to $0.06 \%$. An interpretation of these tendencies requires the analysis of pedigree information. Almost all pedigreed individuals (98.48\%) had both parents known whereas sires were not identified for $1.52 \%$ of animals. On the other hand the average pedigree completeness measured by Cassell's coefficient was equal to only $6 \%$. This aver- 
age coefficient was very low over the first ten years and gradually increased thereafter. Of course, the accuracy of estimation of the inbreeding level via classical tools is determined by the pedigree completeness. It must be noted that in the last periods (end the 1980s and 90s), the Cassell's coefficient achieved the level of $35 \%$. Relatively low pedigree completeness resulted from several factors, such as the maintenance and reproductive systems, incorporation of animals from some Western countries and migration of Polish native sheep flocks. The average inbreeding coefficient for the whole population was low $(0.30 \%)$. As expected, the standard deviation of the inbreeding estimates was relatively large $(0.18 \%)$.

Comparative analysis of inbreeding levels within lines and breeds (see Figure 2) indicates on differences among them. The highest inbreeding levels

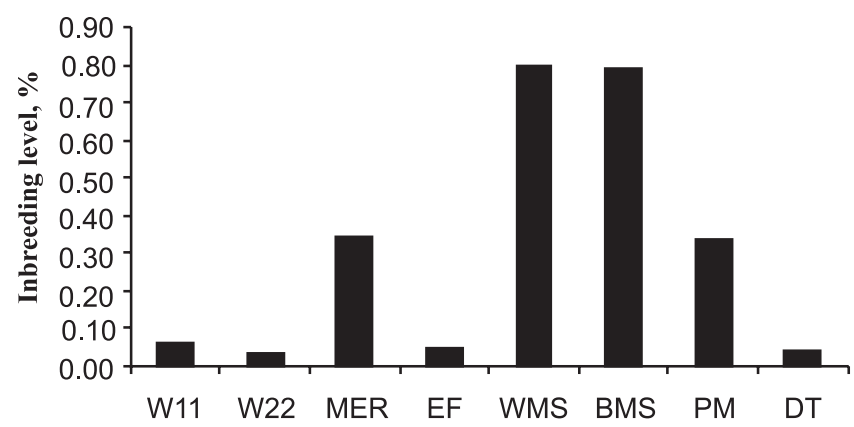

Figure 2. Inbreeding levels (in \%) within lines studied. Note on symbols: W11 - Wielkopolska breed - line I, W22 - Wielkopolska breed - line II, MER - Polish Merino Sheep, EF - East Fresian, WMS - White-head Mutton Sheep, BMS - Black-head Mutton Sheep, PM - prolific-meat line, DT - meat line in Dorset type

were observed for two lines: White-head Mutton Sheep and Black-head Mutton Sheep. They were formed as the synthetic lines (after crossbreeding had been completed) in one flock at the Experimental Station of Złotniki in the second half of the 1980s. The lowest inbreeding levels were registered for the Wielkopolska line (W22) and the meat line in the Dorset type. Standard deviations of the breed group inbreeding coefficients were lowest for W11 (0.009\%), MER $(0.007 \%)$ and PM (0.007), whereas largest variability of the inbreeding estimates were for WMS (0.029\%).

Table 2 shows the partial regression coefficients of inbreeding levels on the two body weight measurements. In general, the inbreeding effects were small. However these lines were found to differ in inbreeding levels $(\mathrm{P}<0.0001)$. Furthermore, the differences among these genetic groups studied were observed. For instance, in three lines (W11, W22 and EF) the effects were negative whereas for lines MER, BMS, PM and DT these effects changed from negative (BW) 
Table 2. Estimates of inbreeding depression - partial linear regression coefficients and their standard deviations (in parenthesis) for BW and FWW (in grams) per 1\% inbreeding

\begin{tabular}{lclrl}
\hline Line/breed & \multicolumn{2}{c}{ BW } & \multicolumn{2}{c}{ FWW } \\
\hline W11 & -11.8 & $( \pm 4.5)$ & -29.65 & $( \pm 15.2)$ \\
W22 & -10.8 & $( \pm 3.5)$ & -2.4 & $( \pm 11.4)$ \\
MER & -3.7 & $( \pm 8.9)$ & 16.6 & $( \pm 27.6)$ \\
EF & -12.09 & $( \pm 7.0)$ & -61.9 & $( \pm 21.7)$ \\
WMS & 16.0 & $( \pm 18.0)$ & -0.3 & $( \pm 67.8)$ \\
BMS & -0.1 & $( \pm 17.0)$ & 18.1 & $( \pm 55.5)$ \\
PM & -6.4 & $( \pm 6.5)$ & 9.6 & $( \pm 20.2)$ \\
DT & -3.5 & $( \pm 13.1)$ & 10.8 & $( \pm 40.6)$ \\
& & & & \\
Whole population & -9.5 & $( \pm 2.3)$ & -11.6 & $( \pm 7.3)$ \\
\hline
\end{tabular}

note on symbols: BW - birth weight, FWW - fourth week weight, W11 - Wielkopolska breed - line I, W22 - Wielkopolska breed - line II, MER - Polish Merino Sheep, EF - East Fresian, WMS White-head Mutton Sheep, BMS - Black-head Mutton Sheep, PM - Prolific-meat line, DT - meat line in Dorset type

to positive (FWW). Non-consistent results in the other lines may result from underestimation of inbreeding level. However, in general looking at the population as a whole, birth weight seems to be more affected by the inbreeding depression than the later measurement.

\section{DISCUSSION}

As already mentioned, a number of reports are available on the inbreeding rate in livestock populations (Sorensen et al., 2005; Parland et al., 2007). The inbreeding level estimates are strongly determined by the two main factors: depth and completeness of pedigree and selection intensity. Selection intensity is often increased by the reproductive technologies being focused on a few superior animals (especially sires) and the application of advanced methods of genetic evaluation. Therefore a higher inbreeding rate has been reported for dairy cattle populations (see e.g., Cleveland et al., 2005). More accurate pedigree information in horses (Gandini et al., 1992) lead to increased precision of inbreeding evaluation, although the inbreeding coefficients were relatively low (Sierszchulski et al., 2005). A high inbreeding level is observed for populations rebuilt from small number of founders, but on the other hand in this case the accuracy is strongly determined by the incompleteness of pedigrees.

Populations analysed in the present study have a variable genetic structure, different breeding histories and genetic improvement strategies, management, etc. Furthermore, as already mentioned the completeness of the pedigree information 
was relatively low and changed over time. A large proportion of missing ancestors in a pedigree may cause an underestimation of the inbreeding level and associated losses arising from inbreeding. The differences of estimated inbreeding level resulting from different pedigree. Completners were shown to range from 1.1 to $14.1 \%$ in Xalda sheep for cohors using 1 to 4 discreate generation equivalents (Alvarez et al., 2008). The inbreeding level estimated for the studied populations was low $(0.3 \%)$. It corresponds with the results given by Mandal et al. (2006) for Muzaffarnagari sheep over an extended period of time. Analla et al. (1999) estimated average inbreeding for six lines to be between 1.4 and 5.3\%. Also estimates of average inbreeding coefficients found by MacKinnon (2003) ranged from 2.2 to $3.8 \%$. Higher inbreeding levels were registered for three Danish sheep populations (Norberg and Sorensen, 2007). Huby et al. (2003) analysed the trend in inbreeding in six French sheep breeds and found rates no higher than $0.4 \%$ per generation. It should be noted that negligible differences between males and females was observed (Barczak et al., 2007).

The lines studied in the current paper were found to differ in their average inbreeding levels. Except for different degrees of completeness of pedigree information, it is associated with diversification of the gene pool of these sheep populations. It must be recalled that the inbreeding trend was positive. Inbreeding can also be considered as fixed effect in routine genetic evaluation in sheep. To our knowledge no reports concerning inbreeding effects on breeding values in sheep are available in literature. Simulation studies conducted by Mehrabani-Yeganeh et al. (2000) suggested that accounting for inbreeding in best linear unbiased prediction of individual genetic effects, although theoretically more correct, does not change the ranking of individuals and does not lead to greater response or greater levels of inbreeding. However, the inbreeding should be included to compute the inverse of the relationship matrix, even though not all pedigrees are complete or traceable to an unselected base population.

As already noted, over recent decades there has been a number of reports concerning the evaluation of inbreeding depression. A majority of them indicate small inbreeding effects on the characters studied. Norberg and Sorensen (2007) showed that birth weight of three breeds (Texel, Shropshire, Oxford Down) decreased respectively by $0.011,0.0082$ and $0.0088 \mathrm{~kg}$ per $1 \%$ inbreeding. Similar results for body weight were obtained by Analla et al. (1999). However, Lamberson et al. (1982) found positive inbreeding influences on birth weight and 60-day weight. In agreement with the results obtained in the present study, low inbreeding depression has been registered for other livestock species populations (Thompson et al., 2002; Sierszchulski et al., 2005).

There are several methodological and biological factors which determine the estimated inbreeding impact on performance traits. It is well known that both negative effects (e.g., lethal and sub-lethal genes) and positive ones (e.g., forming of some 
lines by mating of relatives) exist. Hence, in a given population, "bad" and "good" inbreeding effects are mixed. In attempting to extract negative effects Willis et al. (1996) described a partial inbreeding coefficient, which is defined as the probability that an individual is homozygous for an allele descended from the specified founder. The approach has been used mainly for wild animal populations.

From a statistical point of view, small linear regression coefficients can be affected by nonlinear relationships between inbreeding and a given character. It should be noted that estimates of inbreeding depression obtained via partial quadratic regression for body weight in the studied sheep populations were very close to the ones showed in Table 2 (Barczak et al., 2007).

Some authors (e.g., Norberg and Sorensen, 2007) have suggested the evaluation of inbreeding impact as direct (lamb) and maternal effects. MacKinnon (2003) reported that inbreeding of the lamb had a greater impact on body weight traits than inbreeding of the dam.

In recent years, new approaches based on molecular genetics have provided new opportunities for monitoring of inbreeding in animal populations (Alvarez et al., 2008). It seems that widespread application of them in routine procedures may be restricted for economic reasons. However, the molecular approaches could be employed in the control of parentage in the Polish sheep population.

This study has shown that the inbreeding level of these populations was very low. Both positive and negative inbreeding effects were found. It should be recalled, that the inbreeding level and its effects on body weight have been considerably influenced by the incomplete pedigree information. Hence, further monitoring of the inbreeding rate must be based on classical procedures supported by molecular data.

\section{ACKNOWLEDGEMENTS}

The authors would like to thank an anonymous referee for their useful comments. Dr. Karin Meyer is gratefully acknowledged for her DFREML package programs. The studies of Anna Wolc were supported by the Foundation for Polish Science (contract 113/2007).

\section{REFERENCES}

Álvarez I., Royo L.J., Gutiérrez J.P., Fernández I., Arranz J.J., Goyache F., 2008. Relationship between genealogical and microsatellite information characterizing losses of genetic variability: Empirical evidence from the rare Xalda sheep breed. Livest. Sci. 115, 80-88

Analla M., Montilla J.M., Serradilla M., 1999. Study of the variability of the response to inbreeding for meat production in Merino sheep. J. Anim. Breed. Genet. 116, 481-488 
Barczak E., Wolc A., Szwaczkowski T., Wójtowski J., 2007. Inbreeding and inbreeding depression on productive traits in sheep. In: Proceedings of International Symposium "Perspektiven der der Schaft- und Ziegenhaltung in Mitteleuropa". Iden (Germany), p. 71

Cassell B.G., Adamec V., Pearson R.E., 2003. Effect of incomplete pedigrees on estimates of inbreeding and inbreeding depression for days to first service and summit milk yield in Holsteins and Jerseys. J. Dairy Sci. 86, 2967-2976

Cleveland M.A., Blackburn H.D., Enns R.M., Garrick D.J., 2005. Changes in inbreeding of U.S. Herefords during the twentieth century. J. Anim. Sci. 83, 992-1001

Gandini G.C., Bagnato A., Miglior F., Pagnacco G., 1992. Inbreeding in the Italian Haflinger horse. J. Anim. Breed. Genet. 109, 433-443

Huby M., Griffon L., Moureaux S., Rochambeau H., Danchin Burge C., Verrier E., 2003. Genetic variability of six meat sheep breeds in relation to their genetic management. Genet. Sel. Evol. 35, 637-655

Lamberson W.R., Thomas D.L., Rowe K.E., 1982. The effects of inbreeding in a flock of Hampshire sheep. J. Anim. Sci. 55, 780-786

MacKinnon K.M., 2003. Analysis of Inbreeding in a Closed Population of Crossbred Sheep. MSc Thesis, Virginia Polytechnic Institute and State University (USA)

Mandal A., Roy R., Rout P.K., Sharma N., 2006. The effects of inbreeding on growth of body dimensions of Muzaffarnagari sheep. Proceedings of $8^{\text {th }}$ World Congress on Genetic Applied Livestock Production. Belo Horizonte, MG (Brasil)

Mehrabani-Yeganeh H., Gibson J.P., Schaeffer L.R., 2000. Including coefficients of inbreeding in BLUP evaluation and its effect on response to selection. J. Anim. Breed. Genet. 117, 145-151

Meyer K., 2000. DFREML ver. 3.1. University of New England (Australia)

Norberg E., Sorensen A.C., 2007. Inbreeding trend and inbreeding depression in the Danish populations of Texel, Shropshire and Oxford Down. J. Anim. Sci. 85, 299-304

Parland Mc S., Kearney J.F., Rath M., Berry D.P., 2007. Inbreeding trends and pedigree analysis of Irish dairy and beef cattle populations. J. Anim. Sci. 85, 322-331

SAS, 2002-2003. SAS Procedure Guide. Ver. 9. SAS Institute Inc. Cary, NC

Sierszchulski J., Helak M., Wolc A., Szwaczkowski T., Schlote W., 2005. Inbreeding rate and its effects on three body conformation traits in Arabian mares. Anim. Sci. Pap. Rep. 23, 51-59

Sorensen A.C., Sorensen M.K., Berg P., 2005. Inbreeding in Danish dairy cattle breeds. J. Dairy Sci. $88,1865-1872$

Thompson J.R., Everett R.W., Wolfe C.W., 2000. Effects of inbreeding on production and survival in Jerseys. J. Dairy Sci. 83, 2131-2138

Wiener G., Lee G.J., Woolliams J.A., 1992. Effects of rapid inbreeding and of crossing of inbred lines on conception rate, prolificacy and ewe survival in sheep. Anim. Prod. 55, 115-121

Willis J.H., 1992. Measures of phenotypic selection are biased by partial inbreeding. Evolution 50, 1501-1511

Wójtowski J., 1999. Formation of a synthetic prolific mutton sheep line (in Polish, with English summary). Ann. August Cieszkowski Agr. University Poznan. Sci. Dissert. 299, 1-80 